Sari Anggarawati, Anak Agung Eka Suwarnata

Program Studi Agribisnis, Fakultas Pertanian, Universitas Nusa Bangsa, J1. K.H. Sholeh Iskandar Km. 4, Kelurahan Cibadak, Kecamatan Tanah Sareal, Bogor 16166, Indonesia. e-mail korespondensi: sarianggarawati@gmail.com e-mail: 1985.agungeka@gmail.com

\section{Agribisnis Jambu Mete di Wilayah Perbatasan Kabupaten Timor Tengah Utara - Provinsi Nusa Tenggara Timur}

\author{
(Cashew Agribusiness in Border Areas Timor Tengah \\ Utara Regency, East Nusa Tenggara Province)
}

ISSN: 2721-8589 (media online) ISSN: 2721-8597 (media cetak)

AGRISINTECH

Journal of Agribusiness and Agrotechnology

Vol. 1 No. 1 April 2020

\begin{abstract}
Cashew is a choice crop that can be developed in the Regency of North Central Timor (TTU) which has a dry climate. On the other hand, world market demand is quite high and prices tend to rise. The research sample was 30 farmers and 10 marketing institutions. Data obtained through observation, interviews, and focused discussion in groups, then analyzed descriptively and quantitatively (Farming Feasibility: NPV, IRR, Sensitivity and Marketing Margin) and SWOT Analysis (IFAS, EFAS and SWOT Matrix). The results of the analysis obtained by cashew agribusiness in TTU District consisted of agro-input subsystems, agroproduction subsystems, agro-industry subsystems and agroniaga subsystems and supporting institutions (infrastructure, farmer groups; extension workers; and KUD). Farming feasibility has a Net B/C value of 1,925; NPV Rp32,659,705, -; and IRR 37.05. There are 3 trading system channels, with the trading system consisting of village collectors, Kupang/Atambua traders, wholesalers and retailers. The results of IFAS and EFAS analysis using the SWOT method, obtained an alternative S-O strategy in the development of cashew nuts, namely increasing production with the support of government policy in the assistance of superior seeds; cashew crop integration - cattle as an effort to improve soil fertility; strengthen bargaining positions through farmer groups; and diversification of processed cashew products.
\end{abstract}

Keywords: Agribusiness, cashew, feasibility, marketing, SWOT

\begin{abstract}
ABSTRAK
Jambu mete merupakan tanaman pilihan yang dapat dikembangkan di Kabupaten Timor Tengah Utara (TTU) yang beriklim kering. Di sisi lain, permintaan pasar dunia cukup tinggi dan harga cenderung naik. Sampel penelitian ini adalah 30 petani dan 10 lembaga pemasaran. Data diperoleh melalui observasi, wawancara, dan diskusi terfokus dalam kelompok, kemudian dianalisis secara deskriptif dan kuantitatif (Kelayakan Usahatani: NPV, IRR, Sensitivity dan Margin Pemasaran) serta Analisis SWOT (IFAS, EFAS dan Matrik SWOT). Hasil analisis diperoleh agribisnis jambu mete di Kabupaten TTU terdiri dari subsitem agroinput, subsistem agroproduksi, subsistem agroindustri dan subsistem agroniaga serta lembaga penunjang (infrastruktur, kelompok tani; penyuluh; dan KUD). Kelayakan usahatani memiliki nilai Net B/C 1,925; NPV Rp32.659.705, -; dan IRR 37,05. Terdapat 3 saluran tataniaga, dengan lembaga tataniaga terdiri dari pengumpul desa, pedagang besar kupang/atambua, besar/grosir dan pedagang pengecer. Hasil analisis IFAS dan EFAS dengan menggunakan metode SWOT, diperoleh alternatif strategi $\mathrm{S}-\mathrm{O}$ dalam pengembangan jambu mete, yaitu meningkatkan produksi dengan dukungan kebijakan pemerintah dalam bantuan bibit unggul; integrase tanaman jambu mete - ternak sapi sebagai upaya perbaikan kesuburan tanah; menguatkan bargaining position melalui kelompok tani; dan penganekaragaman produk olahan kacang mete.
\end{abstract}

Kata Kunci: Agribisnis, jambu mete, kelayakan, pemasaran, SWOT 


\section{PENDAHULUAN}

Komoditas perkebunan merupakan andalan pendapatan nasional dan devisa negara Indonesia, hal ini dapat dilihat dari nilai ekspor komoditas perkebunan, sejak Tahun 2013 total ekspor perkebunan mencapai US\$ 29,476 milyar atau setara dengan Rp353,713 triliun (asumsi 1 US\$=Rp12.000). Kontribusi sub sektor perkebunan terhadap perekonomian nasional semakin meningkat dan diharapkan dapat memperkokoh pembangunan perkebunan secara menyeluruh (Perkebunan, Direktorat Jenderal, 2015).

Jambu mete, merupakan salah satu produksi hasil perkebunan di Indonesia. Perkembangan luas areal dan produksi jambu mete di Indonesia mengalami peningkatan. Negara tujuan ekspor jambu mete Indonesia terbesar adalah Vietnam dan India. Indonesia mengekspor hampir $90.08 \%$ ke negara tersebut. Berdasarkan hasil proyeksi yang dilakukan, penawaran jambu mete yang didasarkan pada proyeksi produksinya tahun 2015-2019 mengalami peningkatan sebesar $2,20 \%$ per tahun (Siagian, 2015). Terdapat beberapa wilayah di Indonesia yang memproduksi jambu mete, salah satunya di Kabupaten Timor Tengah Utara.

Kabupaten Timor Tengah Utara (TTU) berada di wilayah perbatasan negara dengan kondisi wilayah sebagian besar berupa lahan kering yang memiliki alam berbukit-bukit (BPS, 2018). Sesuai kondisi alam tersebut, maka pengembangan pertanian di wilayah perbatasan ini difokuskan pada pengembangan pertanian lahan kering (Priyanto \& Diwyanto, 2014). Salah satu tanaman yang cocok dengan kondisi kekeringan dan banyak ditanam masyarakat adalah jambu mete dan sedang diupayakan secara maksimal untuk menggalakkan pembudidayaan tanaman ini kepada masyarakat secara luas. Perkembangan produksi jambu mete berdasarkan data yang diperoleh menunjukkan kondisi yang sempat mengalami penurunan yang cukup drastis, di tahun 2010. Sejalan dengan hasil penelitian Sjah et al., 2010, penurunan produksi juga terjadi di Sumbawa Barat karena harga jambu mete yang rendah (Sjah T., Jamani H., 2010). Meskipun sempat mengalami menurunan, produksi jambu mete menunjukkan arah atau prospek yang cukup menggembirakan karena terus mengalami kenaikan sampai tahun 2016, hal ini ditunjukkan dengan adanya minat petani untuk menanam kembali tanaman ini.

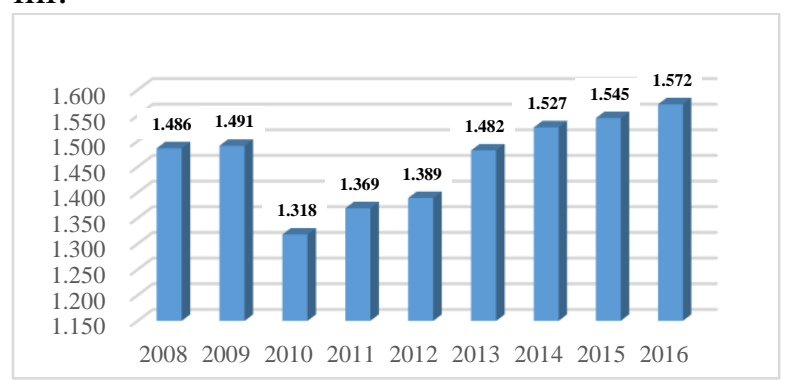

Sumber: Statistik Pertanian Kabupaten Timor Tengah Utara (2018)

Gambar 1. Perkembangan produksi jambu mete tahun 2008 - 2016 di Kabupaten Timor Tengah Utara

Produksi jambu mete tahun 2016 Kabupaten TTU sebanyak 1.572-ton yang dihasilkan dari $11.743 \mathrm{Ha}$ areal penanaman. Produktivitas jambu mete di NTT masih rendah, salah satu faktor penyebabnya adalah luas areal tanaman jambu mete rusak semakin bertambah dan diperlukan rehabilitasi pada areal tersebut. Rehabilitasi kebun atau tanaman dapat ditempuh melalui sejumlah kegiatan seperti pemangkasan, penjarangan dan bahkan penggantian dengan tanaman baru yang memiliki potensi genetik produksi tinggi (Daras, U., \& Tjahjana, 2011). Selain itu perlu pemanfaatan teknologi seperti bahan 
tanaman unggul, perbaikan kondisi biofisik lahan, dan pengendalian hama-penyakit (Daras, 2007).

Perkembangan harga jual mete gelondongan memiliki kecenderungan yang terus naik dari $\mathrm{Rp} 7.000 / \mathrm{kg}$ sampai $\mathrm{Rp} 20.000 / \mathrm{kg}$, namun demikian posisi tawar petani mete di Propinsi NTT umumnya masih lemah. Kondisi ini disebabkan beberapa faktor, antara lain jaringan pemasaran yang cukup panjang, dan rendahnya informasi dan pemahaman petani tentang kualitas mete yang dibutuhkan pasar. Sebagian besar hasil panen jambu mete dipasarkan dalam bentuk mete gelondongan yang masih ada kulitnya, dan masih banyak pengusaha yang lebih senang melakukan ekspor produk bahan mentah (kacang mete mentah) sehingga industri pengolahan kacang mete tidak berkembang di TTU.

Hampir seluruh wilayah Kabupaten TTU terdapat tanaman jambu mete, tanaman ini mudah ditemukan di pekarangan maupun di kebun penduduk, namun demikian usaha jambu mete menjadi suatu usaha bisnis. Usaha agribisnis memiliki kecenderungan menuntut untuk dikembangkan menjadi usaha dengan orientasi bisnis atau keuntungan. Hal itu dapat dilakukan melalui aplikasi konsep pengembangan berdasarkan sistem agribisnis terpadu (Gumbira Said, E., \& A.H., 2001). Menurut Soekartawi, konsep agribisnis sebenarnya adalah suatu konsep yang utuh, mulai dari proses produksi, mengolah hasil, pemasaran dan aktivitas lain yang berkaitan dengan kegiatan pertanian (Soekartawi, 2013).

Secara konsepsional, sistem agribisnis merupakan semua kegiatan mulai dari pengadaan, penyaluran sarana produksi hingga pemasaran produk-produk pertanian dan agroindustri yang berkaitan satu dengan lainnya. Fungsi-fungsi agribisnis terdiri atas kegiatan pengadaan dan penyaluran sarana produksi, kegiatan produksi primer (budidaya), pengolahan (agroindustri), dan pemasaran. Fungsifungsi tersebut disusun menjadi suatu sistem, di mana fungsi-fungsi di atas menjadi subsistem dari sistem agribisnis. Pengembangan harus mengembangkan semua subsistem di dalamnya karena tidak ada satu subsitem yang lebih penting dari subsistem lainnya (Budi, 2020). Tujuan dari penelitian ini adalah pertama melakukan identifikasi subsistem yang ada dalam agribisnis jambu mete, dan kedua melakukan analisis fungsi-fungsi agribisnis dalam subsistem-subsistem yang ada.

\section{METODE PENELITIAN}

Lokasi penelitian ditentukan secara purposive, yaitu di Kabupaten Timor Tengah Utara, Propinsi Nusa Tenggara Timur, sebagai wilayah perbatasan yang kondisinya masih tertinggal. Penelitian dilakukan dari bulan Oktober 2018 - Maret 2019.

Cara pengumpulan data yang dilakukan meliputi 1). Studi dokumen dan literatur, 2). Survei dan observasi lapangan, dan 3). Wawancara. Responden untuk analisis kelayakan usahatani sebanyak 30 orang petani dan untuk analisis pemasaran sebanyak 10 lembaga pemasaran.

Identifikasi subsitem-subsistem yang ada dalam agribisnis jambu mete dilakukan dengan metode diskripsi pada setiap subsistem mulai dari hulu sampai hilir dan keterkaitan antar subsitem yang ada. Analisis fungsi-fungsi agribisnis pada subsistem, meliputi Subsistem Produksi: Kelayakan Usahatani NPV (Net Present Value), IRR (internal rate of return), Payback Period, Kepekaan/Sensitivity). Subsistem Pemasaran: Analisis Pemasaran (Rantai Pemasaran, Margin Pemasaran, Farmer's share, besarnya bagian biaya dan keuntungan masing-masing lembaga pemasaran). 


\section{HASIL DAN PEMBAHASAN}

Subsistem agribisnis terdiri dari: 1). Subsistem pengadaan dan penyaluran sarana produksi; 2). Subsistem produksi primer; 3). Subsistem pengolahan dan 4).
Subsistem pemasaran, serta subsistem penunjang agribisnis (jasa transportasi; jasa komunikasi; jasa perbankan; jasa penyuluhan dan komunikasi; penelitian dan pengembangan; infrastruktur; regulasi; dan kelompok tani).

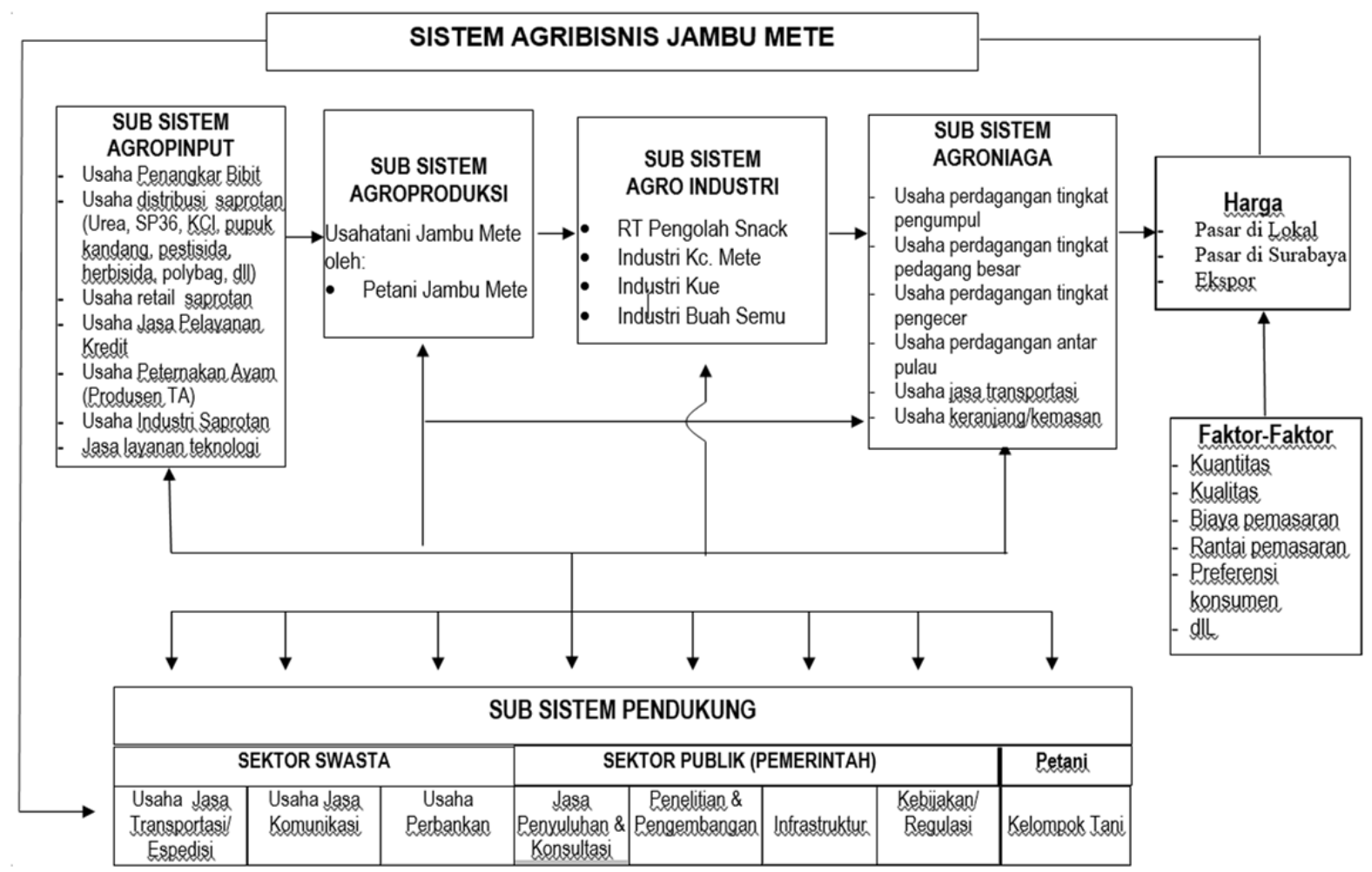

Gambar 2. Sistem agribisnis jambu mete di wilayah perbatasan Kabupaten Timor Tengah Utara

Subsistem agroinput terdiri dari pemasok bibit, pemasok pupuk, pemasok pestisida, pemasok peralatan dan usaha ternak sapi. Penggunaan bibit oleh petani kebanyakan berasal dari kebun sendiri, yang tidak terjamin keunggulannya. Kebutuhan pupuk dapat terpenuhi dari ternak sapi yang dipelihara hampir sebagian besar petani. Ketersediaan peralatan mudah diperoleh di pasar- pasar yang ada di Kawasan tersebut.

Subsistem agroproduksi jambu mete diusahakan oleh 11,206 KK petani yang menanam, baik di pekarangan rumah ataupun di kebun-kebun dengan total luas areal penanaman 11,743 Ha. Keragaan usahatani umumnya dicirikan dengan luas areal yang kecil-kecil kurang dari $1 \mathrm{Ha}$, tenaga kerja seluruhnya berasal dari keluarga tani, penggunaan input dari luar sangat sedikit, penguasaan teknologi budidaya maupun pascapanen terbatas dan lebih dari satu komoditas dalam satu kebun.

Subsistem agroindustri yang ada hanya usaha rumah tangga pembuatan snack kacang mete yang dikemas dengan kantong plastik beraneka ukuran, ampyang kacang mete dan kue kering ditabur kacang mete.

Subsistem agroniaga terdapat lembaga pemasaran terdiri dari pedagang pengumpul tingkat desa, pedagang besar di 
Kota Kupang dan Atambua, pedagang besar/grosir sampai pedagang pengecer.

Lembaga pendukung ada terdiri dari: infrastruktur, kelompok tani; penyuluh; dan KUD. Total jaringan irigasi (primer dan sekunder) adalah sepanjang 73.201,32 m dengan luas daerah irigasi kabupaten dalam kondisi baik mencapai 2.934,50 Ha $(40,33 \%)$ dari 52 Daerah Irigasi (DI) seluas 7.276 Ha. Panjang jalan kabupaten dalam kondisi baik mencapai $405.85 \mathrm{~km}$ (48\%).

Jumlah kelompok tani sebanyak 1.559 , 1.438 kelompok $(92,24 \%)$ masih di Kelas Pemula dan hanya $0,03 \%$ yang masuk Kelas Madya dan tidak ada satupun yang kelas Utama. Sedangkan Gapoktan ada sebanyak 142 kelompok terdiri dari petani/peternak/pekebun.

PPL sebanyak 104 orang terdiri dari 51 orang PNS dan 53 orang THL-TB PP, bila dibandingkan jumlah desa/kelurahan yang ada sebanyak 193 desa/kelurahan, maka jumlah PPL tidak mencukupi. Ditunjang oleh adanya Balai Penyuluhan 24 dan 8 Pos Penyuluhan Desa (POSLUHDES).

Kelembagaan ekonomi yang berkaitan dengan sektor pertanian adalah Koperasi Unit Desa (KUD) dan UKM Pertanian, berdasarkan data Dinas Koperasi dan UKM terdapat 13 KUD dan 942 UKM Pertanian, dari $13 \mathrm{KUD}$, yang aktif dan masih ada kegiatan hanya 6 buah KUD, lebih dari setengah hanya tinggal nama di 15 wilayah kecamatan.

\section{Analisis Fungsi-fungsi Agribisnis Subsistem Produksi: \\ Analisis Kelayakan Usaha Komoditas Jambu Mete}

Biaya usahatani jambu mete terdiri dari biaya investasi, biaya tetap dan biaya operasional sebagaimana disajikan pada tabel berikut.

Tabel 1. Asumsi biaya investasi usaha komoditas jambu mete di wilayah perbatasan Kabupaten Timor Tengah Utara

\begin{tabular}{llccrr}
\hline No & \multicolumn{1}{c}{ Jenis Investasi } & Jumlah & Satuan & $\begin{array}{c}\text { Nilai Satuan } \\
\text { (Rp) }\end{array}$ & \multicolumn{1}{c}{$\begin{array}{c}\text { Total } \\
(\mathrm{Rp})\end{array}$} \\
\hline 1 & Bibit Jambu Mete (ukuran tanam 6x6 m) & 276 & Pohon & 4.700 & 1.297 .200 \\
2 & Cangkul (nilai ekonomis 5 tahun) & 1 & buah & 150.000 & 150.000 \\
3 & Parang (nilai ekonomis 4 tahun) & 2 & buah & 80.000 & 160.000 \\
4 & Tofa/ sabit & 2 & buah & 27.000 & 54.000 \\
\hline \multicolumn{2}{c}{ Jumlah } & & & & 1.661 .200 \\
\hline
\end{tabular}

Sumber: olahan data primer (2019)

Tabel 2. Asumsi biaya-biaya lain usaha komoditas jambu mete di wilayah perbatasan Kabupaten Timor Tengah Utara

\begin{tabular}{|c|c|c|c|c|c|}
\hline No & Uraian & Jumlah & Satuan & $\begin{array}{c}\text { Nilai Satuan } \\
\text { (Rp) }\end{array}$ & $\begin{array}{l}\text { Total } \\
(\mathrm{Rp})\end{array}$ \\
\hline \multicolumn{6}{|c|}{ Biaya Persiapan Lahan } \\
\hline 1 & Penebasan lahan & 1 & hektar & 1.500 .000 & 1.500 .000 \\
\hline 2 & Pengolahan tanah & 1 & hektar & 1.250 .000 & 1.250 .000 \\
\hline 3 & Penanaman & 276 & Pohon & 500 & 138.000 \\
\hline & Jumlah & & & & 2.888 .000 \\
\hline \multicolumn{6}{|c|}{ Biaya Pemeliharaan /tahun } \\
\hline 1 & Pemupukan & 24 & HOK & 70.000 & 1.680 .000 \\
\hline 2 & Pengendalian hama & 9 & HOK & 70.000 & 630.000 \\
\hline 3 & Penyiangan & 27 & $\mathrm{HOK}$ & 70.000 & 1.890 .000 \\
\hline \multirow[t]{2}{*}{4} & Penjarangan pohon 4 orang & 3 & $\mathrm{HOK}$ & 70.000 & 840.000 \\
\hline & Jumlah & & & & 5.040 .000 \\
\hline
\end{tabular}




\begin{tabular}{|c|c|c|c|c|c|}
\hline No & Uraian & Jumlah & Satuan & $\begin{array}{l}\text { Nilai Satuan } \\
\text { (Rp) }\end{array}$ & $\begin{array}{l}\text { Total } \\
\text { (Rp) }\end{array}$ \\
\hline \multicolumn{6}{|c|}{ Biaya Pascapanen } \\
\hline 1 & Angkut panen/ tahun & 1 & kali & 1.000 .000 & 1.000 .000 \\
\hline 2 & Tenaga kerja panen Tahun ke-4 & 38 & HOK & 70.000 & 2.660 .000 \\
\hline 3 & Tenaga kerja panen Tahun ke-5 & 45 & HOK & 70.000 & 3.150 .000 \\
\hline 4 & Tenaga kerja panen Tahun ke- 6 & 51 & HOK & 70.000 & 3.570 .000 \\
\hline 5 & Tenaga kerja panen Tahun ke-7 & 58 & HOK & 70.000 & 4.060 .000 \\
\hline 6 & Tenaga kerja panen Tahun ke- 8 & 62 & HOK & 70.000 & 4.340 .000 \\
\hline 7 & Tenaga kerja panen Tahun ke- 9 & 72 & HOK & 70.000 & 5.040 .000 \\
\hline 8 & Tenaga kerja panen Tahun ke-10 & 88 & HOK & 70.000 & 6.160 .000 \\
\hline \multicolumn{6}{|c|}{ Biaya Saprotan (Sarana Prasarana Pertanian)/ tahun } \\
\hline 1 & Pupuk Urea (tiap tahun berubah) & 74 & $\mathrm{Kg}$ & 2.000 & 148.000 \\
\hline 2 & TSP & 48 & $\mathrm{~kg}$ & 2.200 & 105.600 \\
\hline 3 & KCL (tahun kedua s.d. tahun ke-10 & 33 & $\mathrm{~kg}$ & 2.400 & 79.200 \\
\hline 4 & Pestisida & 2 & liter & 50.000 & 100.000 \\
\hline \multicolumn{6}{|c|}{ Biaya Penyusutan alat / tahun } \\
\hline 1 & Cangkul (nilai ekonomis 5 tahun) & & & & 25.000 \\
\hline 2 & Parang (nilai ekonomis 4 tahun) & & & & 40.000 \\
\hline 3 & Tofa/sabit (nilai ekonomis 3 tahun) & & & & 18.000 \\
\hline & Jumlah & & & & 83.000 \\
\hline
\end{tabular}

Sumber: olahan data primer (2019)

Penerimaan dihitung dari produksi mete dengan tingkat harga sebagaimana gelondongan yang dihasilkan pada tahun ke 4 tanam sampai tahun ke 10 dikalikan disajikan pada tabel berikut.

Tabel 3. Asumsi penerimaan usaha komoditas jambu mete di wilayah perbatasan Kabupaten Timor Tengah Utara

\begin{tabular}{cccccc}
\hline No & Uraian & $\begin{array}{c}\text { Jumlah } \\
\text { Tanaman }\end{array}$ & $\begin{array}{c}\text { Produksi Mete } \\
\text { Gelondong } / \mathrm{kg} / \mathrm{ha}\end{array}$ & Harga/kg & $\begin{array}{c}\text { Total } \\
(\mathrm{Rp})\end{array}$ \\
\hline 1 & Tahun ke-4 & 276 & 552 & $22.000,-$ & $12.144 .000,-$ \\
2 & Tahun ke-5 & 276 & 690 & $22.000,-$ & $15.180 .000,-$ \\
3 & Tahun ke-6 & 276 & 828 & $22.000,-$ & $18.216 .000,-$ \\
4 & Tahun ke-7 & 276 & 966 & $22.000,-$ & $21.252 .000,-$ \\
5 & Tahun ke-8 & 207 & 1035 & $24.000,-$ & $24.840 .000,-$ \\
6 & Tahun ke-9 & 207 & 1242 & $24.000,-$ & $29.808 .000,-$ \\
7 & Tahun ke-10 & 207 & 1553 & $24.000,-$ & $37.272 .000,-$ \\
\hline
\end{tabular}

Sumber: olahan data primer (2019)

\section{Kelayakan Finansial}

Analisa kelayakan finansial ini digunakan untuk melihat apakah suatu proyek dapat dilaksanakan secara ekonomis. Pendekatan ini digunakan untuk melihat kelayakan proyek dari segi finansial dengan menggunakan kriteria investasi (investment criteria) yang meliputi Net Present Value (NPV), Internal
Rate of Return, Benefit Cost Ratio. Berikut disajikan hasil perhitungan tersebut.

Tabel 4. Hasil analisis kelayakan usahatani jambu mete per hektar selama 10 tahun

\begin{tabular}{clc}
\hline No. & \multicolumn{1}{c}{ Hasil Analisis } & \multicolumn{1}{c}{ Nilai } \\
\hline \multirow{2}{*}{1} & INVESTASI & Rp. $1.661 .200,-$ \\
& AWAL & 6,65 \\
2 & DF $(12 \%), 10$ & Tahun \\
3 & TC*DF & Rp. 35.294.669,- \\
4 & TR*DF & Rp. 67.954.374,- \\
\hline
\end{tabular}




\begin{tabular}{clc}
\hline No. & Hasil Analisis & Nilai \\
\hline 5 & Net Benefit & Rp. $97.302 .000,-$ \\
6 & NPV (+) & Rp. $48.055 .998,-$ \\
7 & NPV (-) & Rp. $15.396 .293,-$ \\
8 & TOTAL NPV & Rp. $32.659 .705,-$ \\
9 & GROSS B/C & 2,584 \\
10 & NET B/C & 1,925 \\
11 & RATAAN NPV & Rp. $9.611 .200,-$ \\
12 & PBP & 1,60 \\
13 & IRR $(\%)$ & 37,05 \\
\hline
\end{tabular}

Berdasarkan analisis, dapat dilihat pada Tabel 4, usahatani Jambu Mete per hektar selama 10 tahun memiliki nilai Net B/C 1,925 yang artinya nilai tersebut lebih besar daripada satu, maka usahatani Jambu Mete di wilayah tersebut layak untuk diusahakan karena memberikan keuntungan atas investasi yang ditanamkan. Nilai NPV menunjukkan $>0$, artinya secara finansial usahatani Jambu Mete layak dijalankan karena manfaat yang diperoleh lebih besar dari biaya yang dikeluarkan. Nilai IRR menunjukkan tingkat suku bunga (Discount Rate) lebih besar dari 12\%, maka usahatani Jambu Mete layak untuk dilaksanakan.

Perhitungan analisis sensitivitas ini digunakan apabila terjadi kemungkinan perubahan variabel utama selama umur proyek yaitu menggunakan kombinasi produksi tinggi dan rendah dengan harga tinggi dan rendah, harga tertinggi jambu mete gelondongan Rp22.000, - dan harga terendah Rp12.000, - sedangkan produksi terendah $828 \mathrm{~kg}$ per hektar per tahun, produksi tertinggi $1.950 \mathrm{~kg}$ per hektar. Kemungkinan perubahan variabel, dapat dilihat pada Tabel 5.

Tabel 5. Variabel sensitivitas usahatani jambu mete per hektar di wilayah perbatasan Kabupaten Timor Tengah Utara

\begin{tabular}{cccccc}
\hline \multirow{2}{*}{ No. } & Tahun & \multicolumn{4}{c}{ Variabel } \\
\cline { 3 - 6 } & produksi & $\begin{array}{c}\text { Produksi Tinggi } \\
(\mathbf{K g})\end{array}$ & $\begin{array}{c}\text { Produksi Rendah } \\
(\mathbf{K g})\end{array}$ & $\begin{array}{c}\text { Harga } \\
\text { Tinggi (Rp) }\end{array}$ & $\begin{array}{c}\text { Harga } \\
\text { Rendah (Rp) }\end{array}$ \\
\hline 1 & Tahun ke-4 & 828 & 552 & 20.000 & 12.000 \\
2 & Tahun ke-5 & 966 & 690 & 20.000 & 12.000 \\
3 & Tahun ke-6 & 1.104 & 828 & 20.000 & 12.000 \\
4 & Tahun ke-7 & 1.104 & 966 & 22.000 & 14.000 \\
5 & Tahun ke-8 & 1.449 & 1035 & 22.000 & 14.000 \\
6 & Tahun ke-9 & 1.864 & 1242 & 22.000 & 14.000 \\
7 & Tahun ke-10 & 1.950 & 1553 & 22.000 & 14.000 \\
\hline
\end{tabular}

Sumber: olahan data primer (2019)

Hasil kelayakan usahatani jambu mete per hektar selama 10 tahun berdasarkan sensitivitas harga dan produksi dapat dilihat pada Tabel 6.

Tabel 6. Kelayakan usahatani jambu mete per hektar selama 10 tahun berdasarkan analisis sensitivitas di Kabupaten Timor Tengah Utara

\begin{tabular}{crrrr}
\hline Hasil Analisis & \multicolumn{1}{c}{ PT-HR } & \multicolumn{1}{c}{ PT - HT } & \multicolumn{1}{c}{ PR - HT } & \multicolumn{1}{c}{ PR - HR } \\
\hline Investasi awal & 1.661 .200 & 1.661 .200 & 1.661 .200 & 1.661 .200 \\
DF (12\%) & 4,60 & 4,60 & 4,60 & 4,60 \\
TC*DF & 35.294 .669 & 35.294 .669 & 35.294 .669 & 35.294 .669 \\
TR*DF & 52.988 .147 & 85.134 .047 & 62.898 .905 & 39.181 .655 \\
NPV DF & 17.693 .478 & 49.839 .378 & 27.604 .236 & 3.886 .985 \\
NPV (+) & 33.089 .771 & 65.235 .671 & 43.000 .529 & 19.283 .278 \\
NPV (-) & 15.396 .293 & 15.396 .293 & 15.396 .293 & 15.396 .293 \\
Total NPV & 17.693 .478 & 49.839 .378 & 27.604 .236 & 3.886 .985 \\
Gross B/C & 2,02 & 3,22 & 2,39 & 1,50
\end{tabular}




\begin{tabular}{crrrr}
\hline Hasil Analisis & \multicolumn{1}{c}{ PT-HR } & \multicolumn{1}{c}{ PT - HT } & \multicolumn{1}{c}{ PR - HT } & \multicolumn{1}{c}{ PR - HR } \\
\hline Net B/C & 1,50 & 2,41 & 1,78 & 1,11 \\
Rataan NPV & 6.617 .954 & 13.047 .134 & 8.600 .106 & 3.856 .656 \\
PBP & 2,3 & 1,18 & 1,79 & 3,99 \\
IRR (\%) & 27,6 & 46,20 & 34,00 & 16,15 \\
\hline
\end{tabular}

Sumber: olahan data primer (2019)

Tabel 6 menunjukkan kelayakan usahatani jambu mete dengan variabel sensitivitas yaitu produksi tinggi (PT), produksi rendah (PR), harga tinggi (HT) dan harga rendah (HR). Hasil kelayakan pada empat variasi variabel menunjukkan nilai Net $\mathrm{B} / \mathrm{C}>1$ yang artinya usahatani jambu mete layak untuk diusahakan karena memberikan keuntungan atas investasi yang ditanamkan. Nilai IRR pada tabel juga menunjukkan lebih besar dari 12\%, maka dapat dikatakan usahatani jambu mete pada empat kondisi tersebut layak untuk dilaksanakan.

\section{Subsistem Pemasaran \\ Rantai Tataniaga Komoditas Mete Gelondongan}

Ada dua pasar mete gelondongan, yaitu pasar dalam negeri dan pasar ekspor. Penjualan mete gelondongan dari petani sebagian besar melalui pedagang pengumpul desa, karena tanaman jambu mete yang ditanam per petani tidak banyak dan hasil produk mete gelondongan yang dihasilkan per petani juga tidak banyak, sehingga tidak efisien dipasarkan sendiri. Masalah kuantitas produk dan transporatsi membuat petani bergantung pada pedagang pengumpul ini.

Keberadaan pedagang pengumpul desa membantu pengumpulan mete gelondongan bagi pedagang besar, bila jumlah mete gelondongan telah mencukupi untuk diangkut dengan bak terbuka, pedagang besar tinggal mengambil di pedagang pengumpul desa dan melakukan transaksi penjualan untuk selanjutnya dilakukan sortasi dan dikeringkan sesuai dengan suhu penyimpanan dan menyimpannya sampai diperoleh harga yang bagus dan kuantitas yang cukup selanjutnya dikirim ke PT Gajah Mada di Atambua atau ke pedagang antar pulau di Kota Kupang, selanjutnya dibawa ke luar Pulau Timor melalui pelabuhan Kota Kupang.

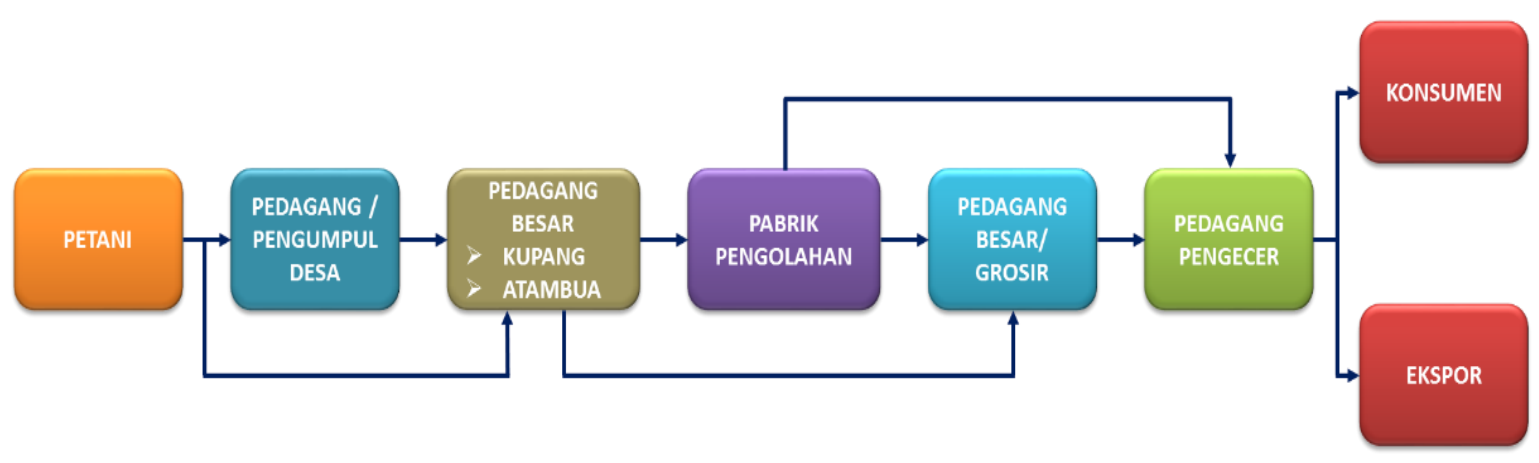

Gambar 3. Rantai tataniaga komoditas jambu mete di wilayah perbatasan Kabupaten Timor Tengah Utara

Hasil penelusuran pemasaran jambu mete di wilayah PKSN Kefamenanu, terdapat tiga (3) saluran pemasaran, yaitu:
Saluran I : Petani - Pengumpul Desa

- Pedagang Besar Kupang/Atambua _ Pedagang Besar/Grosir - 
Pedagang Pengecer Konsumen

Saluran II : Petani - Pedagang Besar Kupang/Atambua Pabrik Pengolahan Pedagang Pengecer Konsumen

Saluran III : Petani - Pedagang Besar Kupang/Atambua Pedagang Besar/Grosir Eksportir

Hasil analisis terhadap ketiga saluran yang ada, Saluran I adalah penjualan kacang mete ke konsumen akhir dalam bentuk sudah terkupas namun belum diolah, Saluran II adalah saluran pemasaran kacang mete yang telah dioloh melalui pabrik pengolahan dan Saluran III adalah pemasaran jambu mete ke luar atau ekspor yang belum diolah.

Harga jual paling tinggi yang diterima petani adalah Saluran II dan III, karena pada saluran ini petani menjual mete gelondongan langsung ke pedagang besar yang datang "menjemput bola" ke desadesa. Sedangkan di Saluran I biasanya petani menjual mete gelondongan ke pengumpul desa biasanya karena adanya kebutuhan yang mendesak.

Pedagang besar atau grosir yang berlokasi di Kota Surabaya berperan penting, baik dalam penjualan dalam negeri maupun ekspor. Grosir melakukan fungsi tataniaga meliputi: penyimpanan; pengupasan mete gelondongan; dan mengekspor. Permintaan ekspor mete selalu dalam bentuk mete mentah yang belum diolah namun sudah dikupas.

Penjualan kacang mete di tingkat konsumen cukup bervariasi, baik yang mentah maupun yang sudah dioleh, harga jual sangat tinggi dalam bentuk yang sudah dikupas, apalagi yang sudah diolah. Berbagai kemasan dapat dijumpai dengan mudah di tingkat konsumen. Berikut disajikan Tabel 7 hasil analisis rantai tata niaga pada ketiga saluran yang ada.

Tabel 7. Analisis rantai tataniaga jambu mete di di Kabupaten Timor Tengah Utara

\begin{tabular}{|c|c|c|c|}
\hline Uraian & $\begin{array}{c}\text { Saluran I } \\
\text { Biaya }(\mathrm{Rp} / \mathrm{Kg})\end{array}$ & $\begin{array}{c}\text { Saluran II } \\
\text { Biaya }(\mathrm{Rp} / \mathrm{Kg})\end{array}$ & $\begin{array}{c}\text { Saluran III } \\
\text { Biaya }(\mathrm{Rp} / \mathrm{Kg})\end{array}$ \\
\hline Harga Jual Petani & 17.000 & 20.000 & 20.000 \\
\hline \multicolumn{4}{|l|}{ PENGUMPUL DESA } \\
\hline Harga Beli & 17.000 & & \\
\hline Harga Jual & 20.000 & & \\
\hline Biaya & 1.500 & & \\
\hline Profit marjin & 1.500 & & \\
\hline Marjin & 3.000 & & \\
\hline RPM & 17,65 & & \\
\hline \multicolumn{4}{|c|}{ Pedagang Besar Kupang/Atambua } \\
\hline Harga Beli & 20.000 & 20.000 & 20.000 \\
\hline Harga Jual & 24.000 & 24.000 & 24.000 \\
\hline Biaya & 2.500 & 2.500 & 2.500 \\
\hline Profit marjin & 1.500 & 1.500 & 1.500 \\
\hline Marjin & 4.000 & 4.000 & 4.000 \\
\hline RPM & 20,00 & 20,00 & 20,00 \\
\hline \multicolumn{4}{|l|}{ Pabrik Pengolah } \\
\hline Harga Beli & & 24.000 & \\
\hline Harga Jual & & 160.000 & \\
\hline Biaya & & 120.000 & \\
\hline Profit marjin & & 16.000 & \\
\hline
\end{tabular}




\begin{tabular}{lrrr}
\hline \multicolumn{1}{c}{ Uraian } & $\begin{array}{c}\text { Saluran I } \\
\text { Biaya }(\mathbf{R p} / \mathbf{K g})\end{array}$ & $\begin{array}{c}\text { Saluran II } \\
\text { Biaya (Rp/Kg) }\end{array}$ & $\begin{array}{c}\text { Saluran III } \\
\text { Biaya (Rp/Kg) }\end{array}$ \\
\hline Marjin & & 136.000 & \\
RPM & & 566,67 & \\
Pedagang Besar/Grosir & & & 24.000 \\
Harga Beli & 24.000 & & 155.000 \\
Harga Jual & 135.000 & & 21.000 \\
Biaya & 100.000 & & 54.000 \\
Profit marjin & 11.000 & & \\
Marjin & 111.000 & & \\
RPM & 462,50 & & \\
Pedagang Pengecer & & & \\
Harga Beli & 135.000 & 160.000 & \\
Harga Jual & 155.000 & 170.000 & \\
Biaya & 10.000 & 3.000 & \\
Profit marjin & 10.000 & 7.000 & \\
Marjin & 20.000 & 6,25 & \\
RPM & 14,81 & & \\
Konsumen/EKSPOR & 135.000 & 170.000 & \\
\hline
\end{tabular}

Sumber: olahan data primer (2019)

Hasil analisis tata niaga jambu mete menunjukkan bahwa marjin terbesar diambil oleh pabrik pengolahan, dimana pabrik pengolahan ini melakukan fungsinya untuk merubah bentuk dari mete gelondongan menjadi kacang mete yang telah diolah dan dikemas. Pengolahan kacang mete bukanlah perkara mudah, mayoritas kacang mete yang sudah dijual bebas merupakan kacang mete yang telah mengalami proses pengolahan yang cukup panjang.

Mahalnya harga kacang mete juga disebabkan dari sulitnya pengolahan dan waktu yang dibutuhkan. Setelah dipanen, kacang mete harus dijemur dulu selama 3 hari sampai benar kering, lalu dipisahkan antara kulit dengan isi kacang menggunakan alat khusus. Proses mengeluarkan kacang dari pembungkusnya ini haruslah hati-hati agar kacang mete tidak ikut rusak, mete yang telah dikupas menggunakan kacip lalu dikeringkan, setelah itu masuk tahap akhir yakni pengelupasan kulit ari mete hingga bersih. Proses satu ini memakan waktu yang cukup lama karena sehari hanya bisa menghasilkan 1 kilogram/orang.

\section{SIMPULAN}

Agribisnis jambu mete di Kabupaten TTU terdiri dari subsitem agroinput, subsistem agroproduksi, subsistem agroindustri dan subsistem agroniaga serta lembaga penunjang (infrastruktur, kelompok tani; penyuluh; dan KUD). Dari subsistem yang ada, yang kurang berkembang subsistem agroindustry, hanya ada industri rumah tangga sangat sederhana.

Usahatani Jambu Mete per hektar memiliki nilai Net B/C 1,925 yang layak untuk diusahakan karena memberikan keuntungan atas investasi yang ditanamkan. Nilai NPV Rp. 32.659.705,menunjukkan $>0$, artinya secara finansial diperoleh manfaat yang lebih besar dari biaya yang dikeluarkan. Nilai IRR 37,05 lebih besar dari 12\%, maka usahatani Jambu Mete layak untuk dilaksanakan.

Terdapat 3 macam saluran tata niaga, harga jual paling tinggi yang diterima petani adalah Saluran II dan III, di mana petani menjual mete gelondongan langsung ke pedagang besar yang datang "menjemput bola" ke desa-desa. 


\section{DAFTAR PUSTAKA}

BPS. (2018). Kabupaten Timor Tengah Utara Dalam Angka 2018. Badan Pusat Statistik.

Budi, A. (2020). Pengertian, Sistem dan Manajemen Agribisnis. Retrieved January 19, 2020, from https://kumpulanilmu.com/ilmupendidikan/pengertian-sistem-danmanajemen-agribisnis/

Daras, U., \& Tjahjana, B. (2011). Teknologi Rehabilitasi Pada Tanaman Jambu Mete. Buletin RISTRI, 2(2), 167-174.

Daras, U. (2007). Strategi dan Inovasi Teknologi Peningkatan Produktivitas Jambu Mete di Nusa Tenggara. Jurnal Litbang Pertanian, 26(1), 25-34.

Gumbira Said, E., \& A.H., I. (2001). Manajemen Teknologi Agribisnis. Jakarta: Ghalia Indonesia.

Perkebunan, Direktorat Jenderal, K. P. (2015). Statistik Perkebunan Indonesia 2013-2015 Jambu Mete. Jakarta: Direktorat Jenderal Perkebunan Kementerian Pertanian.

Priyanto, D., \& Diwyanto, K. (2014). Pengembangan pertanian wilayah perbatasan Nusa Tenggara Timur dan Republik Demokrasi Timor Leste. Pengembangan Inovasi Pertanian, 7(4), 207-220.

Siagian, V. J. (2015). Outlook Jambu Mete. In Pusat Data dan Sistem Informasi Pertanian Kementerian Pertanian (Vol. 53). https://doi.org/10.1017/CBO9781107 415324.004
Sjah T., Jamani H., dan R. (2010). Masalah Usaha Tani Jambu Mete di Kabupaten Sumbawa Barat dan Upaya Penanggulangannya. Agroteksos, 20(1), 65-70. Retrieved from https://www.yumpu.com/id/document /read/12160158/masalah-usahatanijambu-mete-di-kabupaten-sumbawabarat

Soekartawi. (2013). Agribisnis Teori Dan Aplikasinya. Jakarta: Rajawali Pers. 